\title{
How Participation Management Influences Work Engagement: The Mediating Role of Perceived Fit and Leader-Member Exchange
}

\author{
Cheng-Shung Huang ${ }^{1} \&$ Dah-Chuan Gong ${ }^{1}$ \\ ${ }^{1}$ Chang Gung University, Taiwan \\ Correspondence: Cheng-Shung Huang Dr., Department of Industrial \& Business Management, Chang Gung \\ University, 259 Wen-Hwa 1st Road, Kwei-Shan, Tao-Yuan, Taiwan. E-mail: gungho438422@gmail.com
}

Received: October 25, 2019

Accepted: November 14, 2019

Online Published: November 20, 2019

doi:10.5539/ijbm.v14n12p191

URL: https://doi.org/10.5539/ijbm.v14n12p191

\begin{abstract}
How does participative management influence work motivation? The empirical evidence is mixed. We bridged contradictory findings by proposing previously unexamined mediational mechanisms that link participative management practices to work engagement. The results show that participative management practices have the potential to prompt employees to act in line with the organization's goal and values that, in turn, leads to work engagement. In particular, person-organization (PO) fit, need-supply (NS) fit, and leader-member exchange (LMX) are central to setting the relations among participative management practices, perceived fit, and work engagement. The results suggest that participative management should provide multiple avenues to fulfill human needs, thus strengthening employee engagement at work.
\end{abstract}

Keywords: participative management, coaching, leader-member exchange, and work engagement

\section{Introduction}

In regard to total quality management (TQM) success, participative management is often considered a key component in enabling employees to take initiatives in continuous improvement activities, thus linking the TQM program to business success. Participation is not only related to quality improvement, but is also beneficial to felt accountability (Johns, 2006), satisfaction and productivity (Batt \& Applebaum, 1995). With all these factors, HR-focused TQM activities can effectively implement and change a quality improvement program (Projogo \& Cooper \& Brian, 2010). When inviting employees to take part in a quality improvement program, it is postulated that participation-related management practices (e.g., participative leadership, participative management) will help employees to become engaged in such a management program. An engaged employee who is energetic, dedicated to work and absorptive in the learning activities is more related to work outcomes than is satisfaction (see Rich, LePine \& Crawford, 2010). Employee engagement at work, also recognized as an indicator of positive mental health (Huang, Aditya and Elloy, 2016), is powerfully predictive of job performance (Rich, LePine, \& Crawford, 2010).

Like TQM, participative management program seeks to develop human resources through work practices (i.e. job rotation) and leadership (Kolarik \& Fox, 1992). Recently, individual factors and their relations to participation management have drawn the attention of scholars and practitioners, as a critical topic in business excellence. For example, certificated manufacturing systems now cover the issues of health and well-being as indicators of effective system implementation. Past research, however, has paid less attention to the effect of quality practices on employee well-being (Projogo \& Cooper \& Brian, 2010), with little concern paid to the exploration of the relationships between participative management practices and employee engagement at work. We introduced coaching and participative management as antecedents of work engagement, and explored how they affect employee engagement at work through the interplay of employees and external foci such as supervisors and the organization because employees with knowledge, skills and ability matching job demands also show a high level of affective motivation (Spector, 1986).

Participation entails a supportive work environment that encourages employees to make constructive suggestions for quality improvement (Bettencourt, Gwinner \& Meuter, 2001), and helps them to feel empowered at work via managerial guidance. All these participative campaigns contribute to employee adaptation to an array of work conditions, such as a manufacturing system or service delivery process. Thus, the interplay of persons and external factors (i.e. jobs, organizations, and supervisors) has become a noticeable factor that is expected to enhance 
employee adaptation in the workplace.

Despite a variety of well-being indicators, work engagement is an important index of psychological well-being as it reflects positive mental health and positive psychology (Hobfoll, 2002). In the practitioner's point of view, engaged persons are recognized as responsible and dedicated to work, reflecting a state of positive mentality, whereas burnout is syndrome of prolonged strain. Recently, there was a call for positive psychology research to take work engagement as an indicator of positive mental health (see Hobfoll, 2002). For the purpose of prevention and intervention, a sizable body of burnout and engagement studies has paid attention to identifying their environmental and individual antecedents (Langelaan, Bakker, Van Doornen \& Schaufeli, 2006; Maslach et al., 2001; Schaufeli \& Bakker, 2004). Work engagement hereby referred to a positive, fulfilling, affective-motivational state of work-related well-being (Maslach, Schaufeli \& Leiter, 2001). Numerous studies have focused on identifying their environmental (i.e. work system) and individual antecedents (see Schaufeli \& Bakker, 2004) but less on the mechanisms whereby these antecedents affect employee well-being through the interplay of workers and their related work environment. However, how do individual employees respond to participative management? The empirical evidence is mixed. We bridged contradictory findings by proposing a previously unexamined mediational mechanism that will link participative management practices to work engagement. A more thorough understanding of the mechanisms by which participative management influences work engagement will help practitioners to better design training and development programs aimed at getting individual employees to become more involved in their jobs.

Accordingly, we developed a mediational model depicting the relationships between participative management practices (namely, participative management and coaching behavior) and work engagement. In the next section, we draw on Kanfer's (1990) distal-proximal typology of motivational theories to enhance the theoretical validity and the precision of LMX in predicting leadership effects in the workplace. In the current study, we investigated the mediating roles of the types of perceived fit and LMX, along with conscientiousness, coaching, and participation. Previous research has reported that many of these are related to mental illness and work engagement (Spector, 1986).

\section{Theoretical Foundation}

Regarding the effort to improve operational quality and its relation with employee well-being, participation management has often been noted as a part of a humane-oriented work design. However, prior research showed an inconsistent result as to whether participation may be constantly related to work motivation and service quality. For example, participation in self-managing teams resulted in increased self-reported service quality and with sales per employee, whereas quality improvement-related management did not affect performance (Batt, 1999), and even a negative relationship to job satisfaction (see Wood et al., 2012). In a sample of apparel workers, participation was also found not to relate to job satisfaction and work group quality (Batt \& Applebaum, 1995).

The primary reason for the inconsistent results in participative management research is perhaps a missing loop in the link of participative management practices and outcomes. Secondly, there is an incomplete measure of participative management practices, of which traditional measurements on participative management have mostly focused on work system, while neglecting supervisory influence (see Batt \& Applebaum, 1995). Bass (1985) suggests that work environment characterized with more organic and challenging nature in technology and market requires supervisors to employ an employee-focused management style (i.e. participative leadership). We propose an integrated model of person-environment (PE) theory and leader-member exchange theory as two types of mechanisms that help participative management practices linked to work engagement. In the current study, participative management practices include two dimensions: participative work system and coaching leadership style. This measure reflects the philosophy of participative management programs that seek to develop human resources through work practices (e.g., decision-making autonomy) and leadership (Kolarik \& Fox, 1992; Bendoly et al., 2006).

Although the importance of human factors in participative management practices is indisputable, few studies have addressed how participative management practices lead to employee's adaptation in the work environment. Workers are not inclined to immediately reflect on how well they fit the job or the work environment. Instead, employees invest a great deal of energy, time, and job resources before evaluating whether they fit the workplace. If they strive without a harvest and fail to resolve work pressure after a certain amount of investment, they may feel de-motivated and develop a sense of hopelessness because of difficult-to-change work conditions (Huang \& Aditya, 2018). For example, injustice in the workplace reduces employees' acceptance of their organization (incongruence of persons and the organization) while a mismatch of person and job renders employees upset in the workplace. Conversely, congruence of persons and the organization and a good match of persons and jobs help 
employees to act energetically and with dedication to their work (Huang, Aditya, \& Elloy, 2016).

\section{Participative Management, Coaching Behavior, and Work Engagement}

The human factor of quality management is often known as "soft core," and designated to create a supportive environment where the "hard core" of quality management campaign (technology or production aspects) can be implemented by empowering and supporting employees to augment their potential in contribution to the achievement of high-quality outcomes (Rahman \& Bullock, 2002). Furthermore, how can a firm shape a participative work environment to guide employee effort and engagement at work? Previous research has pointed out some solutions: instituting training on the job and improving leadership (Deming, 1986), employee involvement in designing their jobs, and feedback on their quality performance (Prajogo \& Cooker, 2010; Van Dyne et al., 1994). When participation in the decision-making process can help individual employees to better understand organizational goals, it is favorable to realizing person-organization fit.

These practices are essential in enabling employees to thrive at work and utilize their full potential to achieve the objectives of the organization (Dean and Bowen 1994). As well, by inviting employees to join in the work design and keeping them well-informed may lead to their generating opinions which can benefit organizations; feedback is a typical component of participative management and needs the aid of immediate supervisors' assistance to reconcile employee effort and behavior toward realizing organizational values and achieving goals. These participative management practices and supervisory support also introduce employees to take part in managerial decision making. Consequently, human needs are met. A person's intrinsic goal pursuit goes along with a more enduring sense of job engagement (Vansteenkiste et al., 2007). In this regard, self-determination theory (SDT; Ryan \& Deci, 2000) leads us to learn the etiology of how work context can influence human basic needs, such as competence need and autonomy need.

SDT contends that the growth oriented nature of work calls for the fundamental support of employees' inner drive to fulfill their basic needs. Growth-orientation can only arise if individual employees have built sufficient inner resources to nurture this inherent tendency, or found the necessary support in the environment (Richard et al., 2002). The social context can thus support and nurture, or deny and even frustrate individuals' inherent growth tendency. According to SDT, employees are likely to display optimal performance and well-being in a context in which their inherent tendencies are valued. If the work environment is too challenging, controlling or rejecting, individuals' vulnerabilities will dominate and their dysfunctions will become apparent (Van den Broeck, et al., 2008).

In a practical point of view, exercising the practices discussed above will help individual employees develop themselves and adapt to the organization. After a certain amount of time investment, individual employees learn how well they fit in their job and the organization, and maintain a quality relationship with immediate supervisor. Inevitably, PO fit and PJ fit will lead to related need satisfaction (Greguras \& Diefendorff, 2009). Here, we focus on how the interplay of persons with external objects mediates the relationship between participative management practices and work engagement.

\subsection{The Interplay of Persons and External Foci}

The theory of person-environment fit (Edwards, Caplan \& Harrison, 1998) suggests that congruence between attributes of a focal entity (P) and the environment (E) leads to positive outcomes (Lee \& Antonakis, 2014, p. 642) and contributes to psychological well-being. When individuals experience a misfit to the work environment, they may suffer from work strain (French, Caplan \& Harrison, 1982), find their mental health threatened (Ganster \& Schaubroeck, 1991), and perform at a poor level (Kristoff-Brown et al., 2005). Another assumption of PE fit is that individuals typically seek environments that are congruent with their own personal characteristics (Dawis \& Lofquist, 1984; Lofquist \& Dawis, 1991). Such a misfit may stem from how well the workers interact with their organization (i.e. organizational value and goals, and work system and strategy), job demands, job support, and immediate supervisor. For example, Taiwanese culture values harmonious interpersonal relationships. Employees are expected to learn and follow the well-established rules, explicit or implicit, in the workplace other than questioning the rationale behind the way that the work system operates. Participative management opens up a channel to invite employees to join in the work design, even to a chance of changing a company's policy and work system.

The conceptualization of PE fit is complex; however, one way to conceptualize PE is in terms of subjective versus objective fit. Objective fit is said to occur when, in a two-level (e.g., environmental and individual) comparison of characteristics, the characteristics are determined to be highly similar. Perceived fit is a subjective assessment about the interplay between individuals and the environment, and is a useful way to predict work outcome (Kristoff-Brown et al., 2005). 
Work fit is broadly defined as the compatibility between employees and their work environment that occurs when their characteristics are well matched (Kristof-Brown et al., 2005). Typically, perceived fit can be further defined along various foci, such as PJ fit (Cable \& Judge, 1996; Lee \& Antonakis, 2014; Edwards, 1991), PO fit (Kristof, 1996; Kristoff-Brown et al., 2005), or person-supervisor (PS) fit (Bauer \& Green, 1996; Witt, 1998). In addition, PJ fit is conceptually subcategorized into demand-ability (DA) fit and need-supply (NS) fit. Need-supply fit is achieved when environmental tangible or intangible resources (e.g., financial, psychological, task-related, interpersonal, and growth opportunities) meet an individual's needs. When an individual's contributions meet the demands of the environment, DA fit is met. Thus, the difference between NS and DA fit is that in the former, the onus is on the environment to satisfy individual needs, desires, and preferences, whereas, in the latter (DA fit), the onus is on the individual to meet environmental demands (Kristof, 1996; Sekiguchi, 2004). In addition, we include the interplay of employees and supervisors by introducing one of its primary measurements, the quality relationship of leaders and members or leader-member exchange (LMX), which is also a form of persons-supervisors interplay.

The model herein will test (see Figure 1) how participative management practices will affect the interplay of persons and external foci that, in turn, lead to employee engagement at work. The set of hypothesized relationships of work engagement is consistent with social-cognitive theory, which proposes that humans are reflective, self-regulating agents who are not only products of, but also producers of, their environment (Bandura, 1982). This mediational model draws on Kanfer's (1992) proposed environment variables as distal causes of employee well-being that have an effect via more proximal variables such as their motivational state. Similarly, the LMX model proposes that the quality of leader-member exchange is central to the relations among leadership style, work system and outcomes (Dulebohn et al., 2012).

\subsection{The Mediational Role of Perceived Fit and LMX}

All participative management practices and managerial efforts, such as providing feedback, encouraging employees to share ideas through the work arrangement, and collaborative operational activities in work design, guide employees to follow organizational work procedures, and embrace values and goal in a more efficient manner. These notions have been well addressed in the human resource practices and related work system research. Previous research suggests that a social context can support and nurture, or deny and even frustrate individuals' inherent fundamental needs. According to SDT, employees are likely to display optimal performance and well-being in a context in which their inherent tendencies are valued. Ryan and Deci (2001) suggest that individuals in organizations function better with increased work engagement if they enjoy their work settings, i.e. their basic needs are fulfilled, work-life balance are met and personal mindsets flourish.

Following Kanfer's (1992) distal and proximal causes of employee well-being model, we expect the participative management practices-work engagement relationship will be indirect through PO fit, DA fit and NS fit because these three types of fit reflect the extent to which human basic needs are satisfied.

As noted above, managerial efforts help employees to maintain a good quality of subordinate-supervisor relationship under participative work system. Although there is evidence of the mediational role of LMX regarding the relationship of leadership behavior and outcomes, there is a paucity of research empirically exploring how managerial coaching helps subordinates fit in the workplace and subsequently become more engaged in their work through PJ and PO fit. Supervisors seek multi-venues to influence their subordinates. They could deliver intellectual stimulation concerning employee's learning activities and personal mastery (Bass, 1995). They may focus their efforts to aid individual subordinates to adapt to the job by imparting work knowledge and skills, while attempting to strengthen rapport with subordinates under a participative management system (i.e. job rotation and delegation of supervisory authority to subordinates).

In addition, while supervisors promote company policy and strategy, they instruct their subordinates to survive and develop in the organizational work system and culture (see Dulebohn et al., 2012). Meta-analytic reviews (Kristof-Brown et al., 2005) support the relationships of three types of perceived fit and job satisfaction. Based on previous arguments, we expect coaching-work engagement relationship will be mediated by fit perceptions and LMX.

Hypothesis 1 (H1): Participation at Time 2 will predict work engagement at Time 3.

Hypotheses 2 (H2): PO fit will mediate the relationship between participative management practices (coaching and participation) and work engagement.

Hypotheses 3 (H3): PJ fit will mediate the relationships between coaching/ participation and work engagement.

Hypotheses 4 (H4): LMX will mediate the relationships between coaching/ participation and work engagement. 

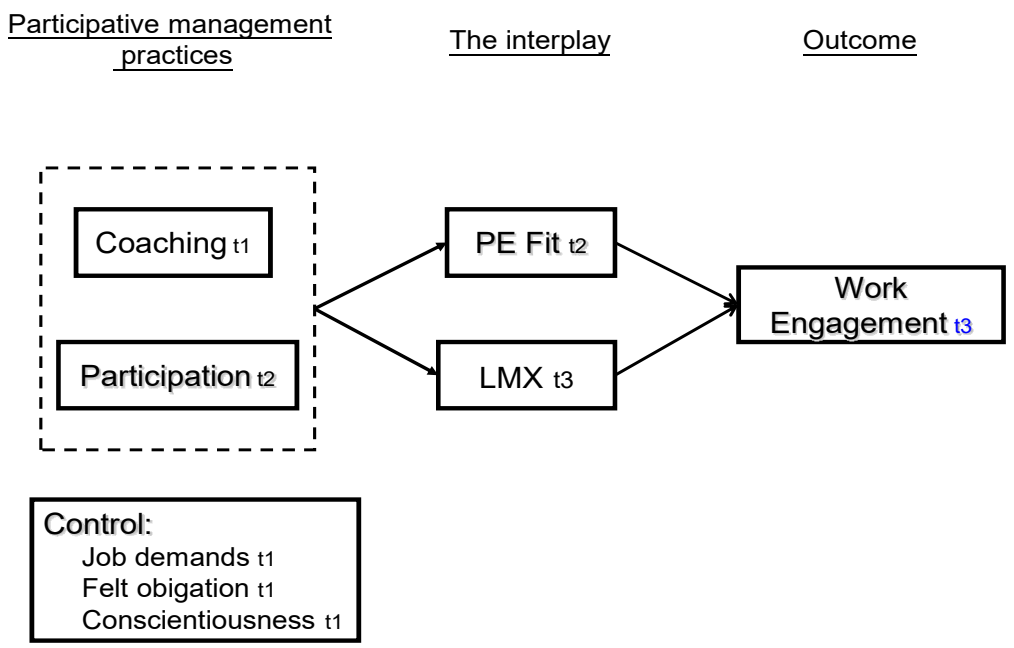

Figure 1. research framework (without direct relationship)

Note. $\mathrm{PE}=$ person-environment, LMX = leader-member exchange

\section{Research Method}

Taiwan's leading position in manufacturing wafer and chips sold to the world is well known. The semiconductor industry in Taiwan has occupied a leading position. Its business has mainly consisted of manufacturing activities in Dynamic Random Access Memory, with chip sales to world-leading companies such as Micro Technology. Questionnaires were distributed and collected with the assistance of a senior management analyst at a wafer manufacturer in Taiwan. The senior management analyst participated in an executive MBA program offered by a university in Northern Taiwan where the authors are employed. One hundred and fifty employees were invited to take part in the employee-version survey, including the measurements of coaching behavior at T1 and participative management at T2, three types of perceived fit (PO, DA, and NS fit) at T2 and LMX at T3, and outcome variable at T3. The effective response rate on the employee questionnaire was $100 \%$. All of the participants were given a remuneration of NT $\$ 100$ (roughly U.S. \$3.30) after completion of the questionnaires at T1. All the respondents were instructed to fill out the questionnaire at their discretion during work time and were assured that all responses would be kept confidential and used only for the purpose of academic research. The responses were returned through an internal delivery system.

The survey was administered in Chinese. The time interval for T1 and T2 was 3 months and 6 months for T2 and T3, respectively. All of the scales in the Chinese version have been used in studies with good reliability and validity. Before distributing the questionnaires, we scrutinized the instrument again. Even though, theoretically, the measurements in the present study were based on well-established ones in English questionnaires, we nonetheless ensured the appropriateness of the wording in the Chinese version. First, the items were translated into Chinese by two native Chinese speakers with graduate degrees. Next, the items were back-translated into English and then checked by one of the first authors to ensure that their meanings were correct.

\subsection{Sample}

The samples at T1, T2 and T3 consisted mainly of men (72.9\%). The hierarchical level: engineer and analyst (89.1\%), supervisor (7.5\%), and assistant and secretary job (3.4\%). Of the longitudinal participants, $22.2 \%$ did not have college degrees (including one with a high school diploma), $51.4 \%$ of respondents had a bachelor's degrees, and $26.4 \%$ had a master's degree or higher. In terms of tenure, $6.3 \%$ of the respondents had less than one year with the firm, $21.5 \%$ had 1 to 3.9 years, $28.5 \%$ had 4 to 6.9 years, and $43.8 \%$ had more than 7 years. Missing data on key demographics were estimated using the full information maximum likelihood (FIML) method, an unbiased and more efficient estimate than other statistical estimation method (Enders \& Bandalos, 2001).

\subsection{Measurements}

Work engagement was nine items of the short version of work engagement scale developed by Schaufeli, Bakker, and Salanova (2006), which encompassed three subscales with three items for each: vigor, dedication, and absorption. Example items are: "At my work, I feel strong and vigorous" (Vigor), "I am enthusiastic about my job" (Dedication), and "I am immersed in my work" (Absorption), $0=$ never, $6=$ always. In the present research, result of the measurement model showing one factor model of work engagement at $\mathrm{T} 3$ was best fitted with data by using 
exploratory factoring analysis. An exploratory factoring analysis on this measure revealed a one-factor model explaining $64.16 \%$ of variance. The reliability of Cronbach's alpha was .95 . Participative management. This measure was adopted from Gurbuz and Mert's (2011) participation dimension of human resource management practices. Items include "participation in developing strategic plan" and "The opportunities to participate in decision-making process." The reliability of the scale $\alpha=.86$.

Managerial coaching. This measure was adopted from Huang's (2005) version of coaching scale with the following items: "my manager helps me to think work problems, rather than provide solutions"; "my manager shows me how to overcome any work difficulties I face"; "my manager provides instructive criticism and useful suggestions to me for achieving tasks." The managerial coaching measure in Chinese version was constructed on a well-theoretical foundation of leadership literature (e.g., Dubrin, 1998) and a pilot study proceeded with an interview process of 15 persons who were full-time employees of an insurance company in Taiwan (Huang, 2005). The Chinese into English version of coaching scale was translated by an American professor and back to the author for further review. The reliability of the scale $\alpha=.91$.

$P O$ fit. This measurement was adopted from Cable and DeRue's (2002) 3-item PO fit scale. An example item is, "The things that I value in life are very similar to the things that my organization values." The reliability of the scale $\alpha=.91$.

DA fit. This was also adopted from Cable and DeRue's (2002) 3-item subjective fit scale. An example item is, "My abilities fit the demands of this job." Cronbach's alpha was .92 .

NS fit. This was also adopted from Cable and DeRue's (2002) NS fit scale. Two example items are, "The attributes that I look for in a job are fulfilled very well by my present job," and "The job that I currently hold gives me just about everything that I want from a job." Cronbach's alpha was .90.

Leader and member exchange. In the present study, Liden and Maslyn's (1998) multidimensional scale of LMX was adapted. The original scale encompasses four sub-dimensions. Granting the dominating influence of the work-unit manager on the dyadic relationship of the person and the supervisor, we replaced work group with "my supervisor," which better reflected the theoretical concept of leader-member relationship quality. Exploratory factorial analysis, using the varimax rotation method, indicated a two-factor structure. The first factor corresponded solely to the "contribution" dimension of the original LMX measurements, while the second factor included the remaining sub-dimensions (i.e. liking, respect, and loyalty sub-dimensions of the original LMX scale). We reviewed the item content of the first factor and found that this factor does reflect the concept of employee citizenship behaviors toward supervisors. For example, "I am willing to apply extra efforts, beyond those normally required, to further the interests of my supervisor." Thus, we skipped this factor and kept the second factor as a measurement of the interplay of subordinates with their supervisors. Previous research also indicated that the current LMX version could result in one single-factor LMX structure (Eisenberger et al., 2010). The reliability of the scale $\alpha=.96$.

Control Variable. This study includes a set of control variables to avoid the confounding effect on work engagement, such as job demand, felt obligation, and conscientiousness (supervisor ratings). Previous research has indicated that job demand is a determinant of work engagement; thus, we took job demand as a control variable to avoid the confounding effect. The measurement of job demand was adopted from Janssen's English version of the psychological job demands scale, which was originally developed by Van Veldhoven and Meijman (1994) in Dutch. An example item is, "Do you have too much work to do?" Items were rated on a four-point Likert scale ranging from $(1=$ never, to $4=$ always $)$. We excluded the only reverse-coded item on the scale because of its poor internal consistency. Additionally, it did not align with the rest of the seven items classified into one factor, resulting in a seven-item measure. After deleting that item, Cronbach's alpha coefficient for job demand was .86 . Conscientiousness is an important individual difference predictor of work effort and productivity. Following the practice from Crant (2000), the present study treated taking charge as an individual-difference variable and was rated by an immediate supervisor as using the third-party person as a source to measure the behavioral pattern; it is considered a reliable method to assess a specific personality trait in personality psychology discipline. Additionally, John (2006) suggests that accountability is a critical characteristic of work context which will determine employee work motivation and behaviors. We used four items from a measurement developed by Britt et al. (2001), in which felt obligation was operationally defined as the degree to which doing well on the job matters, along with the level of felt responsibility and commitment to the job. Items were measured using a six-point Likert-type scale and included: 'I feel obligated to perform my job well'.

\subsection{Analytic Strategy}

Before examining the above hypotheses, we first analyzed the representativeness of the items corresponding to 
the theorized construct. Given the lack of a theoretical and empirical basis, exploratory factor analysis is considered a sensible approach. Exploratory factor analysis (principal axis factoring and varimax rotation) supported the measurement model with 77.63 percent of variance explained by newly produced factors. The results indicated that the items converged well with their respective theoretical construct, and were distinct from the other constructs as studied in the current study. In addition, missing value was replaced by the estimate of FIML.

To examine the mediational hypothesis in the current study, the hierarchical regression model was used to analyze the mediational effects by adopting Baron and Kenny's (1986) suggestions. However, we omitted their increasingly questioned first step of establishing that the antecedent variable is significantly related to the outcome variable, since a non-significant outcome of the first step may be misleading as indirect and direct effects may cancel each other out (James et al., 2006). This misleading might be the case if coaching were reported as lacking a direct effect on work engagement, as shown in Table 2, Step 3. We further carried out an indirect analysis, which is an important procedure to ascertain the mediational effects in the direct links.

\section{Results}

Table 1 presents the means, standard deviations, and correlations of the variables studied. Except for the correlation between participation and DA fit, the inter-correlations among two antecedents (managerial coaching and participation), PO fit, DA fit, NS fit, LMX, and work engagement were positively correlated $(p<.05)$, as predicted. It is worth noting that the preliminary analyses indicated that none of demographic variables was systematically related work engagement. Thus, to facilitate the model estimation, we did not include demographic factors in the following analyses of hypotheses testing.

Table 1. Descriptive Statistics and Intercorrelation between Study Variables $(\mathrm{N}=150)$

\begin{tabular}{|c|c|c|c|c|c|c|c|c|c|c|c|}
\hline & Mean & SD & 1 & 2 & 3 & 4 & 5 & 6 & 7 & 8 & 9 \\
\hline 1.JD & 2.53 & .47 & & & & & & & & & \\
\hline 2.Felt_oblig & 4.80 & .66 & .08 & & & & & & & & \\
\hline 3.Consci & 4.12 & .85 & $.14^{+}$ & $.22^{* *}$ & & & & & & & \\
\hline 4.Coaching & 4.07 & .92 & .05 & $.21^{*}$ & .00 & & & & & & \\
\hline 5.Particip & 4.04 & .76 & $.14^{+}$ & $.21^{* *}$ & .05 & $.35^{* *}$ & & & & & \\
\hline 6.PO fit & 3.89 & .76 & -.11 & $.26^{* *}$ & .09 & $.18^{*}$ & $.27^{* *}$ & & & & \\
\hline 7.DA fit & 4.23 & .72 & -.11 & .13 & .09 & $.21^{*}$ & .13 & $.30^{* *}$ & & & \\
\hline 8.NS fit & 3.89 & .85 & -.08 & .03 & -.01 & $.24^{* *}$ & $.45^{* *}$ & $.46^{* *}$ & $.52^{* *}$ & & \\
\hline 9.LMX & 3.95 & .99 & .09 & $.31^{* *}$ & $.18^{*}$ & $.58^{* *}$ & $.48^{* *}$ & $.23^{* *}$ & $.22^{* *}$ & $.31^{* *}$ & \\
\hline 10.Engage & 3.64 & .83 & -.00 & $.41^{* *}$ & $.14^{+}$ & $.25^{* *}$ & $.29^{* *}$ & $.42^{* *}$ & $.19^{*}$ & $.34^{* *}$ & $.49^{* *}$ \\
\hline
\end{tabular}

$\mathrm{JD}=$ job demand; Felt_oblig $=$ felt obligation; Particip = participation; Consci $=$ conscientiousness; PO = person-organization; DA = demand-ability; NS = need-supply; LMX = leader-member exchange; Engage = work engagement.

As the Step- 3 model in Table 2 revealed, participation was positively related to work engagement at T3 ( $\beta=.18, p$ $<.05)$. Thus, H1 was supported. With respect to the mediational hypothesis, H2, as reported in Table 2, the mediational analyses were presented through Step 1 to 4 . The results of step 1-1, 1-2, 1-3 and 1-4 showed that participation was positively related to PO fit $(\beta=.22, \mathrm{p}<.01)$, NS fit $(\beta=.45, \mathrm{p}<.001)$ and LMX $(\beta=.29, \mathrm{p}$ $<.001)$, except for DA fit $(\beta=.07, \mathrm{~ns}$.). In addition, coaching was positively related to DA fit $(\beta=.17, \mathrm{p}<.05)$ and LMX $(\beta=.45, \mathrm{p}<.001)$ while supervisor-rated conscientiousness scores were positively related to only one mediator, LMX $(\beta=.13, \mathrm{p}<.05)$. To examine four mediators' direct effect on work engagement, as reported in Table 2, PO fit, NS fit and LMX were positively related to work engagement. Given that PO fit, NS fit and LMX met Baron and Kenny's (1986) precondition of the meditational effect, these three mediators were further included in the following analyses. The set of potential mediators was entered into the equation of Step 3, and the results of 
the step-4 equation indicated that PO fit, NS fit, and LMX were significantly related to work engagement (PO fit: $\beta=.22, \mathrm{p}<.01 ; \mathrm{NS}$ fit: $\beta=.18, \mathrm{p}<.1$; LMX: $\beta=.39, \mathrm{p}<.001)$. At this stage of the hierarchical regression analysis, the results indicated that PO fit, NS fit and LMX mediated the relationship between participation and work engagement.

Table 2. Results of hierarchical regression tests for hypotheses 1 4

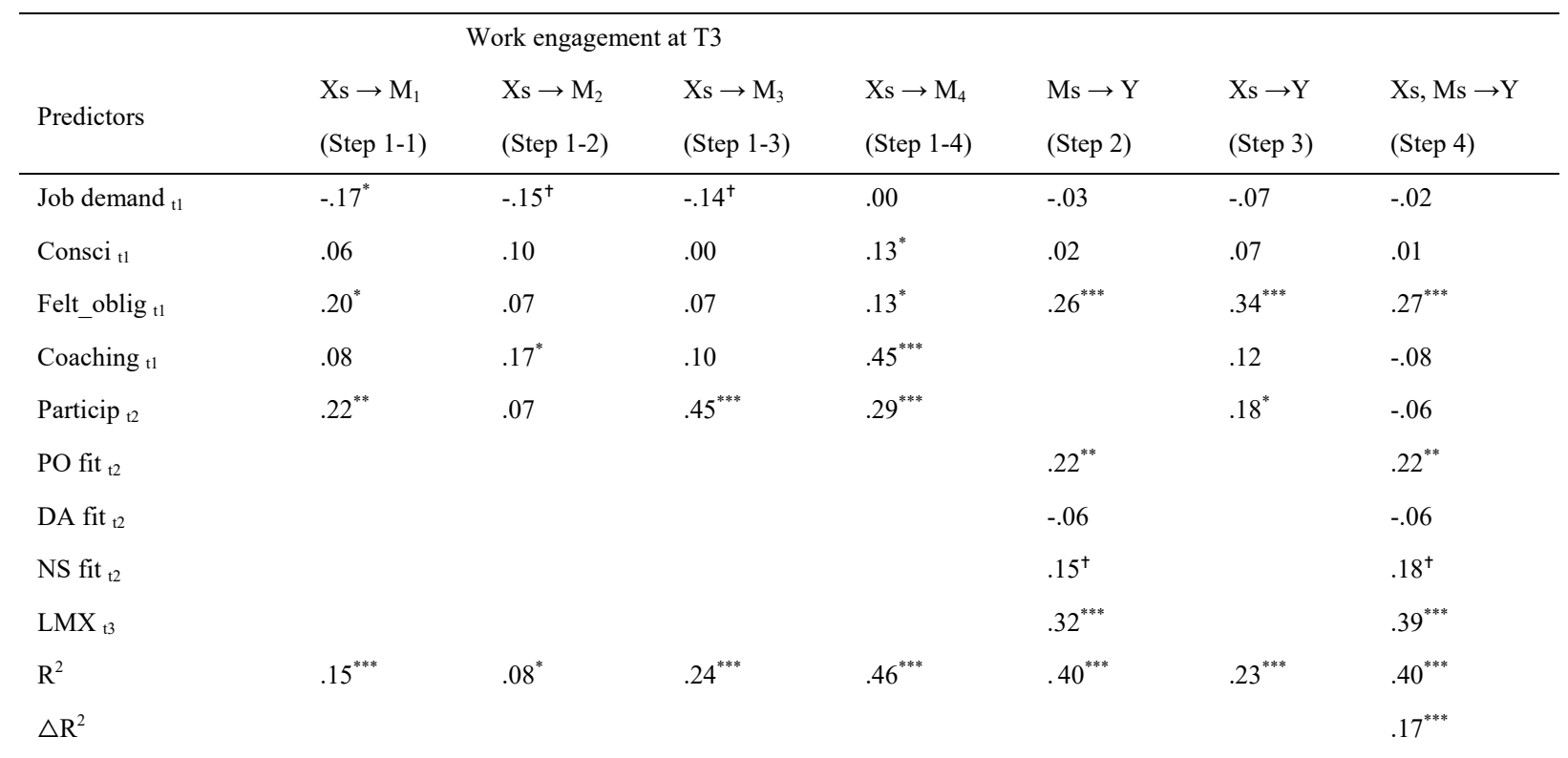

$\dagger p<0.1,{ }^{*} p<.05,{ }^{* *} p<.01,{ }^{* * *} p<.001$.

Felt_oblig = felt obligation; Particip $=$ participation; Consci $=$ conscientiousness; $\mathrm{PO}=$ person-organization; DA $=$ demand-ability; NS = need-supply; LMX = leader-member exchange.

PO fit denoted as $M_{1}$, DA fit $=$ denoted as $M_{2}$, NS fit denoted as $M_{3}$, and LMX denoted as $M_{4}$.

According to the results of preliminary statistical analyses by applying hierarchical regression technique, we further tested the indirect effects of PO fit, NS fit, and LMX on the relationships among participation, coaching, and work engagement using a bias-corrected method with 1000 bootstrap iterations (Frazier et al., 2004); the results were consistent with the hierarchical regression analyses for work engagement.

With respect to the indirect effect of the mediators, the results of the bias-corrected method indicated only an indirect effect of participation-PO fit-work engagement (lower bound $=.01$, upper bound $=.17, \mathrm{p}<.05$ ), but not for coaching-PO fit-work engagement $(\mathrm{p}=.25)$. Likewise, the results showed only an indirect effect of participation-NS fit-work engagement (lower bound $=.04$, upper bound $=.23, \mathrm{p}<.01$ ) but not for coaching -NS fit-work engagement $(p=.25)$. Regarding the mediating effect of LMX, the results showed an indirect effect on the relationship between participative management practices and work engagement (for coaching: lower bound $=.13$, upper bound $=.35, \mathrm{p}<.001$; for participation: lower bound $=.07$, upper bound $=.27, \mathrm{p}<.001$ ). As a result, we confidently conclude that LMX acts as a mediator in the relationship between participation and work engagement; thus, H4 was supported.

\section{Discussion}

The present research proposes a mediating mechanism holding four mediators (namely, three types of fit perceptions and LMX), and thereby contributes by enhancing the theoretical validity and precision of participative management literature. The current research is important because it contributes to the refinement of participation management literature in the following ways: first, the present study integrates participation management, work engagement, fit theory and LMX literature by exploring the mediational role of employee's fit perceptions toward the organization, job, and the supervisor in the relationship between participation management and employee engagement at work. Second, a strong point of our findings is derived from data collected at different points in time. The use of time-lagged data is a recommended measure for controlling possible common source problems. Obtaining measurements of the independent and dependent variables from different points in time alleviates 
common source problems in a cross-sectional study, such as the effects of mood states, implicit theories, social desirability tendencies, and leniency (Podsakoff et al., 2003). Furthermore, by employing these guidelines, we assessed workplace participation, supervisor-rated conscientiousness and fit perceptions with work engagement.

The primary purpose of the current study was to explore the processes through which participation relates to employee work engagement. The results of the current study indicate that PE fit is important in relation to employee well-being (work engagement). DA fit, PO fit, NS fit, and LMX are potentially central to the relations among participative management, the above-mentioned mediators, and work engagement. In addition, managerial coaching will enhance the employee perception of demand-ability fit and, of course, prove beneficial to a good relationship with direct reports. Consistent with previous leadership research, LMX mediates the relationship between coaching leadership and work engagement.

Wood et al. (2012) reported that employee involvement is positively related to job satisfaction. In the current study, we extended the extant participation management literature to attest that it helps employees fit in their organization and to have a good relationship with immediate supervisors; in turn, this leads to an engaged employee. According to the social exchange model, participative management can be regarded as an indicator of perceived organizational support (POS), which is highly accepted in the workplace because POS is meant to meet basic human needs, and is related to felt obligation (Eisenberger et al., 2010), effort. The relationships among participative management practices, PO fit, and work engagement are an example of this logic. If organizations take greater care regarding the needs of employees, they will feel strong support from their organizations. In return for this support, employees can internalize the organization's goals and values, and use their full potential to get involved in the organizational processes. The impetus of getting better PO fit in the workplace can increase their work engagement.

The results also suggest that participation management practices have the potential to prompt employees to act in line with the organization's goals and values that guide work engagement through the PO-fit mechanism. It is quite a common practice in a manufacturing system that a participative management program encourages all the employees to embrace human resources as the core component of implementing continuous improvement activities on product quality. Participative management helps employees adapt to the work environment by receiving feedback from top management and immediate supervisors; they then work in a way that meets the supervisor's expectations as well as the organizational values and goals.

In addition, participative management attempts to enable employees to join in decision-making and work design. With the discussions at work or offering their voice in meetings, employees can provide constructive suggestions and receive direct feedback from management and immediate superiors, as well as resources allocation supplied by the organization or opportunities to break through the organizational constraints for realizing greater efficiency. Accordingly, the work system will become more directed toward fulfilling employees' basic needs, such as competence need and autonomy need (Ryan \& Deci, 2000). Consequently, a participative work system will benefit personal well-being.

Having a quality relationship with one's supervisor often contributes to employee engagement in the workplace. Employees with a good supervisor-subordinate relationship not only perform more effectively, but also have better mental health (Dulebohn et al., 2012). The current study supports this expectation, and suggests that participative management practices indirectly influence work engagement through LMX. This phenomenon could be explained by the contention of self-determination theory that the growth-oriented nature of individuals requires fundamental nutrients, termed as relatedness-, autonomy- and competence-need. The growth-oriented nature can only result if individuals have built sufficient inner resources to nourish this inherent tendency, or have found the necessary support in the environment. The participative context can thus support and nurture, or deny and frustrate, individuals' inherent growth tendency because the philosophy of participative management encourages the development of human potential for the achievement of quality improvement (Kolarik \& Fox, 1992).

Our results suggest that PO fit, NS fit and LMX are central to the relations among participative management practices, the interplay of persons with their external objects, and work engagement, implying in part that the autonomy-, relatedness-, and competence-need (Greguras \& Diefendorff, 2009) are fulfilled. Furthermore, if there is a context in which their inherent tendency and talents are valued, individual employees can best be motivated by supporting their endogenous potential, such as within a participative management system.

Our results support this expectation and were, in part, consistent with previous research (e.g. Cable \& Edwards, 2004), indicating that PE fit influences employee outcomes both directly and indirectly. The results of the role of NS fit in relation to outcomes showed that it directly and indirectly influenced psychological illness. We found that when employees perceive that their needs are being met on the job, they feel less cynical toward work and report 
fewer problems with psychological distress.

In sum, the current findings suggest that participative management provides a work system with multi-venues to fulfill human needs, thus promote employee engagement at work.

\section{Limitations and Future Research}

Some limitations lead to our suggestions for future research. First, our pioneering study was a sample from a Taiwanese context. Despite the importance of the current findings, their application to Western society may be somewhat restricted. It is important to try to replicate our findings in a non-Taiwanese sample, if only to confidently conclude the role of fit. Nevertheless, our research illuminates a profound issue that arises in the advent of employee well-being in Asian countries, in which average work hours are longer than in most developed countries. Second, we chose LMX to explore the interaction of persons and supervisors pertaining to work engagement. It is not uncommon for research to put the interplay of persons and their external environments as mediator, or for research to explore how this subject relates to employee well-being and performance. Studies on how participative management and leadership affect work engagement through the mechanism of PO fit, NS fit and LMX are meaningful and helpful in understanding the etiology of how employee fit and employee interactions with their supervisors affect work motivation. Future research could extend our research to productivity to explicate the relationships among participative management, work engagement, and productivity.

The current study paves the way for a future exploration of the profile of engaged employees. The results from the current study suggest that when individual employees have a sense of fitting well in the organization and the job, while enjoying a good relationship with their immediate supervisor, they become cognitively and emotionally energized, dedicated to work, and absorptive in the workplace.

Third, we took emotional job demand as a control variable in the present study and presented its impact on work engagement. We suggest that future research extend the research to production operations under highly demanding job conditions (i.e. full capacity of production), and on how participative management and coaching impact employee well-being through the avoidance of burnout. For example, do quantitative workload and qualitative job demands have similar effects on mental health?

Fourthly, a merit of data collection in different time interval which make the strength in inference causation, our data on antecedent group were not gathered in an identical period of time. For example, the measure of coaching was collected at Time 1 whereas participative management measure was collected at Time 2 . In an ideal state, data-gathering strategy meeting the requirements of longitudinal research could substantially strengthen the causation of the relationship between variables of interest. Finally, the modern organization is an arena where employers and employees intensively interact and seek ways to fit in. Therefore, in addition to PO, PJ, and PS fit, there is a need for research inclusion of the concept of work group fit. Person-group fit also needs to be explored in relation to work outcomes.

\section{References}

Baron, R. M., \& Kenny, D. A. (1986). The moderator-mediator variable distinction in social psychological research: Conceptual, strategic, and statistical considerations. Journal of Personality and Social Psychology, 51, 1173-1182. http://dx.doi.org/10.1037/0022-3514.51.6.1173

Bass B. M. (1985). Leadership and performance beyond expectations. Human Resource Management, 25(3), 481-484. https://doi.org/10.1002/hrm.3930250310

Batt, R. \& Applebaum, E. (1995). Worker Participation in Diverse Settings: Does the Form Affect the Outcome, and if so, who Benefits? British Journal of Industry Relations, 33(3), 353-378. http://dx.doi.org/10.1111/j.1467-8543.1995.tb00444.x

Batt, R. (1999). Work organization, technology, and performance in customer service and sales. Industrial \& Labor Relations Review, 52, 539-564. https://doi.org/10.1177/001979399905200403

Bendoly, E., Donohue, K., \& Schultz, K. L. (2006). Behavior in operations management: Assessing recent findings and revisiting old assumptions. Journal of Operations Management, 24, 737-752. http://dx.doi.org/10.1016/j.jom.2005.10.001

Cable, D. M., \& DeRue, D. S. (2002). The convergent and discriminant validity of subjective fit perceptions. Journal of Applied Psychology, 87, 875-884. http://dx.doi.org/10.1037/0021-9010.87.5.875

Cable, D. M., \& Edwards, J. R. (2004). Complementary and supplementary fit: A theoretical and empirical integration. Journal of Applied Psychology, 89, 822-834. http://dx.doi.org/10.1037/0021-9010.89.5.822 
Crant, J. M. (2000). Proactive behavior in organizations. Journal of Management, 26(3), 435-462. http://dx.doi.org/10.1177/014920630002600304

Dean, J. W., \& Bowen, D. E. (1994). Management theory and total quality: Improving research and practice through theory development. Academy of Management Review, 19(3), 392-418. http://dx.doi.org/10.5465/amr.1994.9412271803

Diefendorff, J. M., \& Greguras, G. J. (2009). Contextualizing emotional display rules: Examining the roles of targets and discrete emotions in shaping display rule perceptions. Journal of Management, 35(4), 880-898. http://dx.doi.org/10.1177/0149206308321548

Dulebohn, J. H., Bommer, W. H., Liden, R. C., Brouer, R. L., \& Ferris, G. R. (2012). A meta-analysis of antecedents and consequences of leader-member exchange integrating the past with an eye toward the future. Journal of Management, 38, 1715-1759. https://doi.org/10.1177/0149206311415280

Eisenberger, R., Karagonlar, G., Stinglhamber, F., Neves, P., Becker, T. E., Gonzalex-Morales, M. G., \& Steiger-Mueller, M. (2010). Leader-member exchange and affective organizational commitment: The contribution of supervisor's organizational embodiment. Journal of Applied Psychology, 95(6), 1085-1103. http://dx.doi.org/10.1037/a0020858

Enders, C. K., \& Bandalos, D. L. (2001). The relative performance of full information maximum likelihood estimation for missing data in structural equation models. Structural Equation Modeling, 8(3), 430-457. http://dx.doi.org/10.1207/S15328007SEM0803_5

Frazier, P. A., Tix, A. P., \& Barron, K. E. (2004). Testing moderator and mediator effects in counseling psychology research. Journal of Counseling Psychology, 51(1), 115-134. http://dx.doi.org/10.1037/0022-0167.51.1.115

Greguras, G. J., \& Diefendorff, J. M. (2009). Different Fits Satisfy Different Needs: Linking Person-Environment Fit to Employee Commitment and Performance Using Self Determination Theory. Journal of Applied Psychology, 94(2), 465-477. http://dx.doi.org/10.1037/a0014068

Gurbuz, S. \& Mert, I. S. (2011). Impact of the strategic human resource management on organizational performance: evidence from Turkey. The International Journal of Human Resource Management, 22(1), 138-162. http://dx.doi.org/10.1080/09585192.2011.565669

Halbesleben, J. R., \& Bowler, W. M. (2007). Emotional exhaustion and job performance: The mediating role of motivation. Journal of Applied Psychology, 92, 93-106. http://dx.doi.org/10.1037/0021-9010.92.1.93

Hobfoll, S. E. (2002). Social and psychological resources and adaptation. Review of General Psychology, 6, 307-324. http://dx.doi.org/10.1037/1089-2680.6.4.307

Huang, C. S. (2005). Leadership and human capital: Coaching and unit morale. NSC Project report (NSC 93-2416-H-182-012). Taipei: Ministry of Technology.

Huang, C.-S., \& Simha, A. (2017, July 20). The mediating role of burnout in the relationships between perceived fit, leader-member exchange, psychological illness, and job performance. International Journal of Stress Management. https://dx.doi.org/10.1037/str0000077

Huang, C. S., Simha, A., \& Elloy, D. (2016). Exploring the relationships among person-organization fit, work engagement and positive mental health. Journal of Business Administration, 109, 21-40. https://doi.org/10.3966/102596272016060109002

Johns, G. (2006). The essential impact of context on organizational behavior. Academy of Management Review, 31(2), 386-408. https://doi.org/10.5465/amr.2006.20208687

Kolarik, W. J., \& Fox, R. R. (1992). Total quality theory and practice. Proceedings of the1992 Pacific Conference on Manufacturing, 966-973.

Kristof-Brown, A. L., Zimmerman, R. D., \& Johnson, E. C. (2005). Consequences of individuals' fit at work: A meta-analysis of person-job, person-organization, person-group, and person-supervisor fit. Personnel Psychology, 58, 281-342. https://doi.org/10.1111/j.1744-6570.2005.00672.x

Lee, Y. T., \& Antonakis, J. (2014). When preference is not satisfied but the individual is: How power distance moderates person-job fit. Journal of Management, 40, 641-675. https://doi.org/10.1177/0149206311436080

Liden, R. C., \& Maslyn, J. M. (1998). Multidimensionality of leader-member exchange: An empirical assessment through scale development. Journal of Management, 24, 43-72. https://doi.org/10.1016/S0149-2063(99)80053-1 
Maslach, C., Schaufeli, W. B., \& Leiter, M. P. (2001). Job burnout. Annual Review of Psychology, 52, $397-422$. https://doi.org/10.1146/annurev.psych.52.1.397

Podsakoff, P. M., MacKenzie, S. B., Lee, J. Y., \& Podsakoff, N. P. (2003). Common method biases in behavioral research: A critical review of the literature and recommended remedies. Journal of Applied Psychology, 88, 879-903. https://doi.org/10.1037/0021-9010.88.5.879

Prajogo, D. I., \& Brian, K. (2010). The effect of people-related TQM practices on job satisfaction: A hierarchical model. Production Planning \& Control, 21(1), 26-35. http://dx.doi.org/10.1080/09537280903239383

Rahman, S., \& Bullock, P. (2002). Soft TQM, hard TQM, and organizational performance relationships: An empirical investigation. Omega, 33(1), 73-83. https://doi.org/10.1016/j.omega.2004.03.008

Rich, B. L., LePine, J. A., \& Crawford, E. R. (2010). Job engagement: Antecedents and effects on job performance. Academy of Management Journal, 53(3), 617-635. https://doi.org/10.5465/AMJ.2010.51468988

Richer, S. F., Blanchard, C., \& Vallerand, R. J. (2002). A motivational model of work turnover. Journal of Applied Social Psychology, 32, 2089-2113. http://dx.doi.org/10.1111/j.1559-1816.2002.tb02065.x

Ryan, R. M., \& Deci, E. L. (2000). Self-determination theory and the facilitation of intrinsic motivation, social development, and well-being. American Psychologist, 55, http://dx.doi.org/10.1037/0003-066X.55.1.68

Schaufeli, W. B., \& Bakker, A. B. (2004). Job demands, job resources, and their relationship with burnout and engagement: A multi-sample study. Journal of Organizational Behavior. 25(3), 293-315. http://dx.doi.org/10.1002/job.248

Schaufeli, W. B., Bakker, A. B., \& Salanova, M. (2006). The measurement of work engagement with a short questionnaire a cross-national study. Educational and psychological Measurement, 66, 701-716. https://doi.org/10.1177/0013164405282471

Spector, P. E. (1986). Perceived control by employees: A meta-analysis of autonomy and participation at work. Human Relations, 39(11), 1005-1016. https://doi.org/10.1177/001872678603901104

Van den Broeck, A., Vansteenkiste, M., \& De Witte, H. (2008). Self-Determination theory: A theoretical and empirical overview in occupational health psychology in Occupational health psychology. In European perspectives on research, education, and practice (Vol. 3 pp. 63-88). Nottingham University Press.

Van Veldhoven, M. J. P. M., \& Meijman, T. F. (1994). The measurement of psychosocial job demands with a questionnaire (VBBA). Amsterdam, the Netherlands: Nederlands Instituut voor Arbeidsomstandigheden.

Vansteenkiste, M., Neyrinck, B., Niemic, C., Soenens, B., de Witte, H., \& Van den Broeck, A. (2007). Examining the relations among extrinsic versus intrinsic work value orientations, basic need satisfaction, and job experience: A self-determination theory approach. Journal of Occupational and Organizational Psychology, 80, 251-277. https://doi.org/10.1348/096317906X111024

Witt, L. A. (1998). Enhancing organizational goal congruence: A solution to organizational politics. Journal of Applied Psychology, 83, 666-674. https://doi.org/10.1037/0021-9010.83.4.666

Wood, S., Van Veldhoven, M., Croon, M., \& de Menezes, L. M. (2012). Enriched job design, high involvement management and organizational performance: The mediating roles of job satisfaction and well-being. Human Relations, 65(4), 419-445. http://dx.doi.org/10.1177/0018726711432476

\section{Copyrights}

Copyright for this article is retained by the author(s), with first publication rights granted to the journal.

This is an open-access article distributed under the terms and conditions of the Creative Commons Attribution license (http://creativecommons.org/licenses/by/4.0/). 